\title{
Efficacy of self-designed intraoral appliances in prevention of cheek, lip and tongue bite after local anesthesia administration in pediatric patients
}

\author{
Wala A. Alghamidi ${ }^{1}$, Sondos B. Alghamdi ${ }^{2}$, Jawaher-Ahmad Assiri ${ }^{1}$, Abeer A. Almathami ${ }^{3}$, Zuhair-Motlak \\ Alkahtani ${ }^{4}$, Rafi A. Togoo ${ }^{5}$ \\ ${ }^{1}$ BDS, Department of Pediatric Dentistry \& Orthodontic Sciences , King Khalid University College of Dentistry, Abha, Saudi \\ Arabia \\ ${ }^{2}$ BDS, Teaching Assistant Department of Pediatric Dentistry \& Orthodontic Sciences , King Khalid University College of Dentis- \\ try, Abha, Saudi Arabia \\ ${ }^{3}$ BDS, Department of Restorative Dentistry, King Khalid University, Abha, Saudi Arabia \\ ${ }^{4}$ DPD (Doctor of Pediatric Dentistry), Assistant Professor, Department of Pediatric Dentistry \& Orthodontic Sciences , King Kha- \\ lid University College of Dentistry, Abha, Saudi Arabia \\ ${ }^{5}$ MDS, Professor, Department of Pediatric Dentistry \& Orthodontic Sciences, King Khalid University College of Dentistry, Abha, \\ Saudi Arabia
}

Correspondence:

Department of Pediatric Dentistry \& Orthodontic Sciences King Khalid University College of Dentistry

Abha, Saudi Arabia

ratogo@kku.edu.sa

\begin{abstract}
Alghamidi WA, Alghamdi SB, Assiri JA, Almathami AA, Alkahtani ZM, Togoo RA. Efficacy of self-designed intraoral appliances in prevention of cheek, lip and tongue bite after local anesthesia administration in pediatric patients. J Clin Exp Dent. 2019;11(4):e315-21.

http://www.medicinaoral.com/odo/volumenes/v11i4/jcedv11i4p315.pdf
\end{abstract}

Received: 04/12/2018

Accepted: 18/02/2019

\begin{abstract}
Background: The occurrence of self-inflicted soft tissue injuries following administration of local anesthesia in pediatric patients who have received dental treatment has been reported. Aim: To evaluate the attitudes and knowledge regarding cheek, lip, and tongue bite post administration of local anesthesia among dental practitioners in Saudi Arabia. Additionally, the efficacies of three types of intraoral appliances on the prevention of self-harm were evaluated in pediatric patients.

Material and Methods: A total of 301 practitioners were provided with a questionnaire consisting of 9 items. In addition, three types of intraoral appliances made of polyethylene terephthalate were designed as follows: design 1 (consisted of an anterior extension with numerous perforations); design 2 (had a buccal flap extension); and design 3 (comprised of serrated borders). The appliances were placed in the oral cavities of 45 children (age, 3-15 years) immediately after the completion of the dental procedure. The patient was asked to retain the appliance for $3 \mathrm{~h}$. After $24 \mathrm{~h}$, both parents and children were required to respond to a checklist to evaluate the effectiveness the appliances.

Results: Almost half of the dental practitioners had never encountered self-inflicted soft tissue injury in children after local anesthesia administration. About $60 \%$ of the dentists were of the opinion that

provision of adequate instructions after treatment could prevent the occurrence of lip, cheek, and tongue biting. Furthermore, among the three appliances used, design 1 was most well accepted.

Conclusions: Intraoral appliances used in this study may be considered for use to prevent self-inflicted soft tissue trauma in children following administration of local anesthesia.
\end{abstract}

Key words: Cheek biting, lip biting, intraoral appliance, local anesthesia. 


\section{Introduction}

Self-inflicted injuries such as lip and cheek biting are known to be potential complications of local anesthesia following dental treatment, especially in pediatric patients (1-3). Altered sensations or numbness in the lips, cheeks, and tongue last for a few hours post-treatment, and may lead to self-harm in children (2). Recently, an $\alpha$-antagonist called phentolamine mesylate was shown to reduce the duration of soft tissue associated anesthesia and the incidence of self-injury after a dental procedure $(4,5)$. Similarly, submucosal injection of hydralazine $\mathrm{HCl}$ was demonstrated to be safe and effective for the reduction of the duration of local anesthetic-induced anesthesia and its associated problems in 50 patients who received inferior alveolar nerve block (6).

The fabrication of intraoral appliances for prevention of self-inflicted soft tissue injury has been reported in special needs patients (7-9) and in those with habitual biting of the oral mucosa $(10,11)$. Polyethylene terephthalate has been used in the fields of medicine $(12,13)$ and dentistry, particularly orthodontics (14). This material has been used for the fabrication of orthodontic aligners, mouth guards, and splints $(15,16)$.

In the present study, we aimed to evaluate the opinions of dental practitioners in Saudi Arabia, regarding cheek, lip, and tongue bite post administration of local anesthesia. In addition, the efficacies of three types of intraoral appliances in the prevention cheek, lip, and tongue bite were evaluated.

\section{Material and Methods}

This study was approved by the Ethical Clearance Committee at King Khalid University, Abha, Saudi Arabia. Informed consent was obtained from all participants or their guardians prior to enrollment.

A survey questionnaire designed in English and Arabic was provided to 301 dental practitioners in the cities of Abha and Khamis Mushayat, Saudia Arabia (Table 1,1 continue). The questionnaire consisted of 9 items pertaining to the occurrence of cheek, lip, and tongue bite after local anesthesia administration in children.

In addition, three types of intraoral appliances made of polyethylene terephthalate, a transparent and flexible material, were fabricated for the children (Fig. 1). The appliances were fabricated in three standard sizes based on the age of the patient: 3-6, 6-9, and 9-12 years. Furthermore, the three designs used in this study were as follows: design 1, which consisted of an anterior extension with numerous perforations (Fig. 1A,B); design 2, which had a buccal flap extension (Fig. 1C,D); and design 3, with serrated borders (Fig. 1E,F). The efficacies of the appliances were tested on 45 children aged between 3-15 years. Informed consent was obtained prior to inserting the appliance. The appliance was placed in the oral cavity immediately after the completion of the dental procedure in patients who received inferior alveolar nerve block using $2 \%$ lidocaine with epinephrine $(1: 50,000$ or $1: 100,000)$. Each patient was asked to retain the appliance in the mouth for $3 \mathrm{~h}$. The patients were recalled after $24 \mathrm{~h}$, and both parents and children were required to respond to a checklist to evaluate the effectiveness and comfort of the appliance (Table 2).

-Statistical analysis

Data was collected using a MS Excel sheet, and analyzed using SPSS, version 20.0 (SPSS Inc, Chicago, IL, USA) to get the frequency distribution of responses. Chi-square test was used to compare frequency of responses from subjects for 3 different designs of appliances.

\section{Results}

A summary of the responses of the 301 dental practitioners to the questionnaire are shown in table 1 . Ninety-six $(31.9 \%)$ practitioners reported that they were familiar with post-extraction lip, cheek, and tongue bite; in addition, 102 (33.9\%) had rarely encountered such cases in their practice, while 103 of them had occasionally encountered a few of these cases. The majority 191 $(63.5 \%)$ of the cases reported were in children aged 3 to 6 years, and $89(32.6 \%)$ cases were noted between the ages of 6 to 9 years.

When asked about the reason for the lip, cheek, and tongue bite after the local anesthesia, 117 (38.9\%) practitioners blamed the dentists for not providing appropriate instructions after treatment, $98(32.6 \%)$ attributed it to the age of the patient, while $84(27.9 \%)$ believed that refusal to follow instructions provided by the dentists may lead to self-injury in the children.

As seen in Table 1, more than half of the practitioners $(183 / 301 ; 60.8 \%)$ stated that the provision of proper postoperative instructions could prevent lip, cheek, \& tongue bite, whereas less than one-third of them (97; $32.2 \%$ ) indicated that it may prevent the trauma to some extent only. A total of 184 (61.1\%) practitioners reported that they always provided postoperative instructions to their patients, while 86 (28.6) stated that they gave it most of the time; on the other hand, instructions were rarely or never provided by $14(4.7 \%)$ and $17(5.6 \%)$ of the 301 practitioners, respectively. The majority of the practitioners $(266 ; 88.4 \%)$ responded that most cases of lip, cheek, and tongue bite were encountered with inferior alveolar nerve block, while $25(8.3 \%)$ and $7(2.3 \%)$ reported that self-inflicted soft tissue was commonly seen after infiltration and posterior superior alveolar nerve block, respectively. Most of the practitioners $157(52.2 \%)$ dealt with the cases in a palliative manner, whereas $110(36.5 \%)$ of them did not provide any treatment to the patients. Furthermore, 244 (81.1\%) dental practitioners had never used or read about the use of an appliance that could prevent the occurrence of complications after local anesthesia administration; 39 (13\%) 
Table 1: Responses of the dental practitioners to the questionnaire.

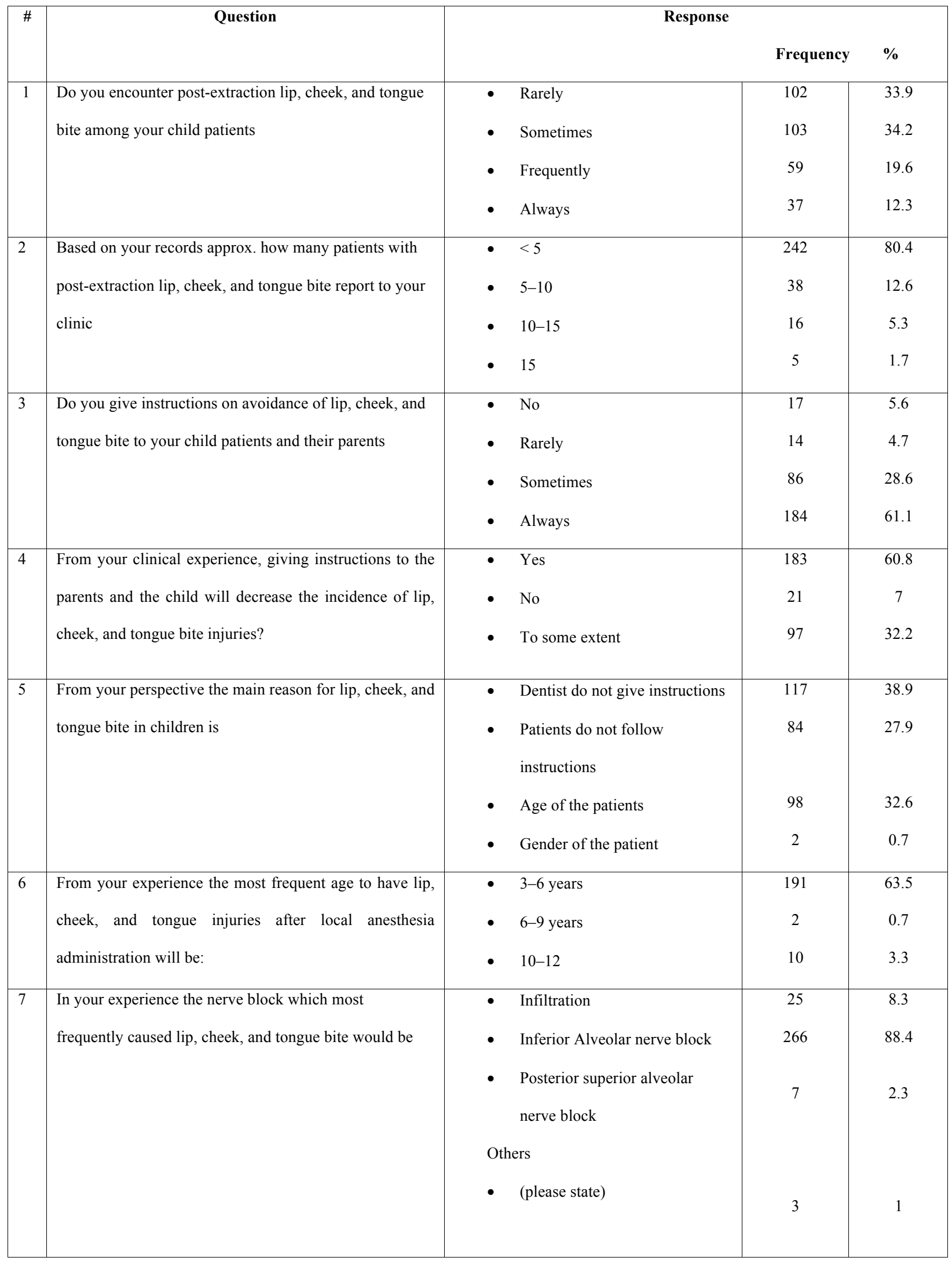


Table 1 continue: Responses of the dental practitioners to the questionnaire.

\begin{tabular}{|c|c|c|c|c|}
\hline 8 & $\begin{array}{l}\text { Your treatment of post-extraction lip, cheek, and tongue } \\
\text { bite injuries }\end{array}$ & $\begin{array}{ll}\text { - } & \text { No treatment } \\
\text { - } & \text { Palliative } \\
\text { - } & \text { Others }\end{array}$ & $\begin{array}{l}110 \\
157 \\
34\end{array}$ & $\begin{array}{l}36.5 \\
52.2 \\
11.3\end{array}$ \\
\hline 9 & $\begin{array}{l}\text { Have you ever used an appliance to prevent post- } \\
\text { extraction lip, cheek, and tongue bite injuries }\end{array}$ & $\begin{array}{ll}\text { - } & \text { Yes } \\
\text { - } & \text { No } \\
\text { - } & \text { No, but I know about it }\end{array}$ & $\begin{array}{l}18 \\
244 \\
39\end{array}$ & $\begin{array}{c}6 \\
81.1 \\
13\end{array}$ \\
\hline
\end{tabular}

A

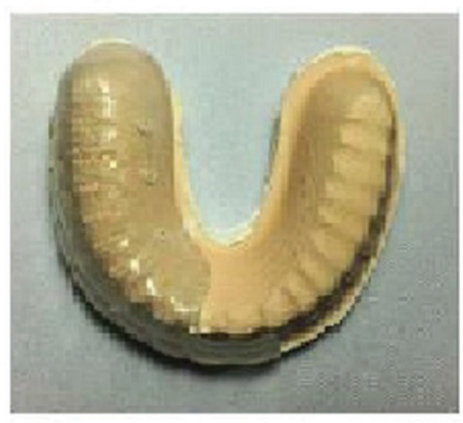

C



$\mathbf{E}$

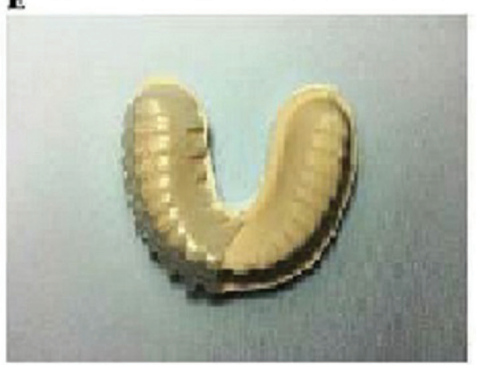

B



D



F

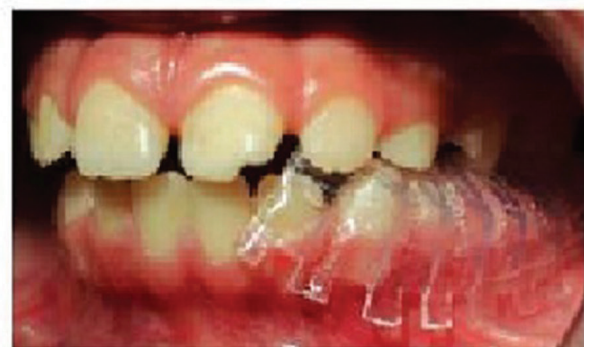

Fig. 1: Photomicrographs showing the three types of appliances on the dental cast (A, C, and E) and in the oral cavity (B, D, and F). Design 1 (A, B) consisted of an anterior extension with numerous perforations, design 2 (C, D) had a buccal flap extension, and design 3 (E, F) comprised of serrated borders.

had only read about them, and $17(6 \%)$ reported having used such appliances.

Out of the three types of intraoral fabricated in this study, design 1 received the most favorable response when compared with designs 2 and 3 based on the checklist created. Design 1 was superior in comfort, and received positive responses from $83.3 \%$ of the children. Moreo- ver, $100 \%$ of children and $91.67 \%$ of parents did not report any complaints with design 1 while $91.7 \%$ and $66.7 \%$ of children and parents respectively, had no complaints for design $2 ; 66.67 \%$ and $58.33 \%$ of children and parents respectively, did not mention any complaints regarding design 3 (Fig. 2).

$33.3 \%$ and $8.8 \%$ of parents and children respectively 
Table 2: Checklist for the children and parents with regard to the three types of appliances fabricated.

\begin{tabular}{|l|l|l|l|}
\hline \multirow{2}{*}{ Number } & \multicolumn{1}{c|}{ Question } & \multicolumn{2}{c|}{ Response } \\
\cline { 3 - 4 } & & Yes & No \\
\hline 1 & The child reported back with cheek or lip bite & & \\
\hline 2 & The child was comfortable with the appliance & & \\
\hline 3 & The child retained the appliance in the mouth for the time advised & & \\
\hline 4 & The child reported specific problems/complications with the appliance & & \\
\hline 5 & The parents had comments about the appliance & & \\
\hline
\end{tabular}

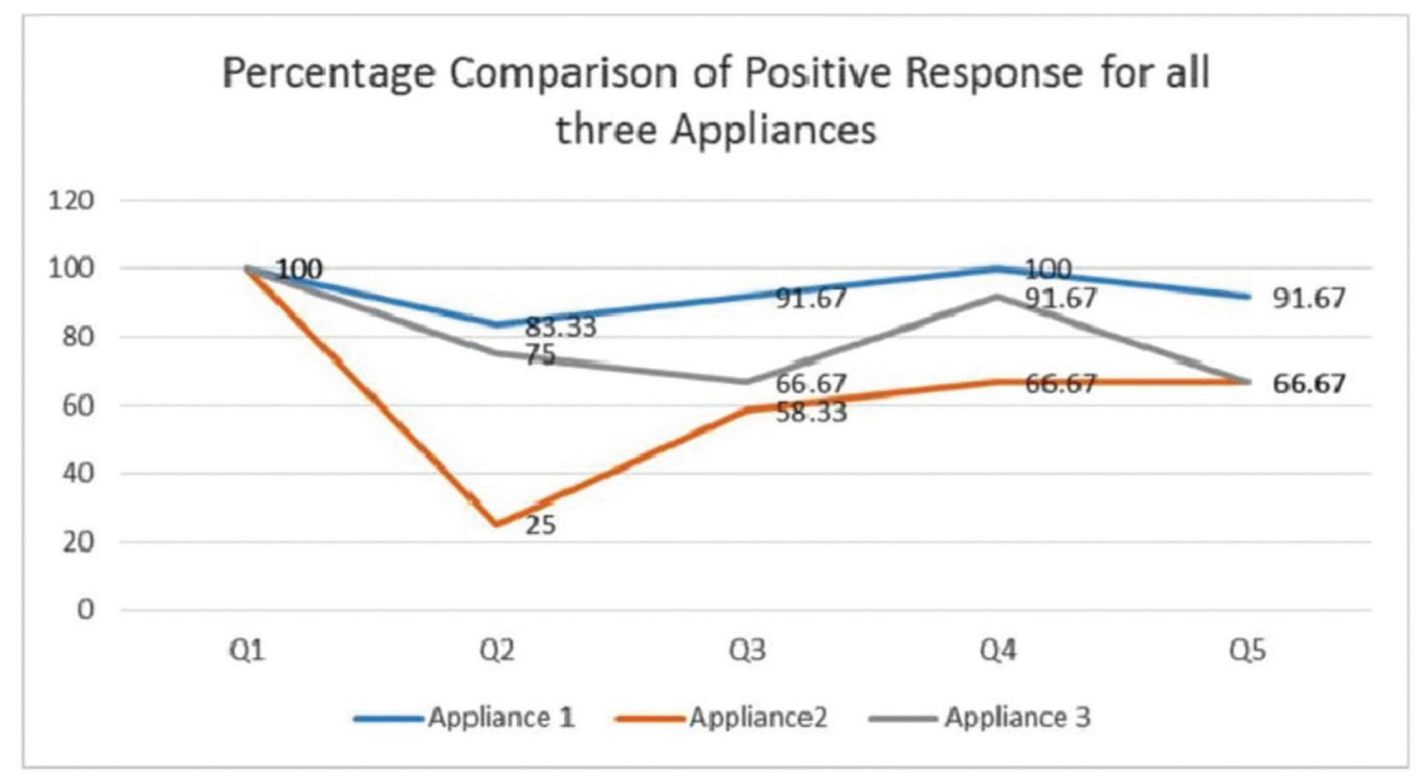

Fig. 2: Graph showing the percentage of favorable responses received from the 45 children and their parents to the five questions regarding the three different types of appliances. Design 1 received the most favorable responses among the three.

had some complaints about design 2 while $42.2 \%$ and $33.33 \%$ of parents and children respectively had few complaints about design 3 . All three types of appliances were retained in the mouth for the recommended periods of time advised by the children, except for design $2(58.3 \%$ of the children).

\section{Discussion}

The effects of anesthesia can last for several hours irrespective of the type of local anesthesia used $(1,17)$. Moreover, it has recently been shown that the use of mandibular infiltrations, instead of blocks does not reduce the occurrence of these injuries (18); however, according to Vempaty and Robbins (2017), the use of short acting anesthetics may prevent self-harm in children (2). The most common local anesthetic agents used in dentistry are $2 \%$ lidocaine with epinephrine $(1: 100,000)$. In the current study, the two agents were administered via inferior alveolar nerve block at a ratio of 1:50,000 or $1: 100,000$. Nevertheless, approximately $90 \%$ of the dental practitioners in this study identified inferior alveolar nerve block as the mode of anesthesia that most commonly caused lip, cheek or tongue biting in children. More than half the number of dental practitioners in the present study had rarely or infrequently encountered lip, cheek or tongue biting among pediatric patients who had received local anesthesia for dental treatment. In addition, the majority of the children presenting with these conditions belonged to the 3-6 age group. These findings are similar to those reported by College et al. (2000), wherein $13 \%$ of 320 children aged 2 to 18 experienced soft tissue trauma after local anesthesia, with the highest frequency observed in children below 4 years of age (19). In another study, 14 (4\%) out of 349 children (age range, 2-18) presented with lip biting after local anesthesia (3).

Interestingly, with regard to the question about the provision of instructions to the patients, $61 \%$ of the dentists responded that they always provided the required instructions to the patients after treatment, whereas the proportion of practitioners who rarely or never gave instructions was about $10 \%$. Similarly, nearly $61 \%$ of the 
dentists believed that the provision of instructions to the patients could decrease the occurrence lip, cheek, and tongue biting after local anesthesia, while $7 \%$ did not endorse the opinion. Approximately $40 \%$ of the practitioners felt that lack of provision of adequate instructions accounted for the occurrence of these self-inflicted injuries, while nearly $30 \%$ blamed the patients for not following the instructions. It has been suggested that creating awareness of the time of action of the local anesthetic agents, and the possibility of self-injury may help prevent or reduce the occurrence of lip, cheek, and tongue biting among children $(1,2)$.

Most self-inflicted injuries following local anesthesia are minor and resolve on their own, or may require palliative care such as analgesics or chlorhexidine rinses. More than half of the dentists in the current study have provided palliative care for the patients when required. Ram et al. (2010) reported that the licking of a popsicle after dental treatment can reduce the incidence of soft tissue trauma in children, while Vempaty and Robbins (2017) suggested that avoiding food during this time might prevent the occurrence of lip, cheek, and tongue biting $(2,20)$. However, the use of intraoral appliances to prevent the occurrence of soft tissue injury following local anesthesia has not been reported so far.

Intraoral appliances have been used for the prevention of self-inflicted soft tissue injuries in children with developmental and psychological problems. Removable shields made of soft silicone, soft polyvinyl splints, mouth guards, and cheek plumpers have been used to prevent tongue, lip, and cheek biting (11,21-23). In the present study, three types of intraoral appliances made of polyethylene terephthalate were fabricated and tested on 45 children aged between 3-15 years. Polyethylene terephthalate glycol is a clear, light, resistant, and elastic material that has been used for orthodontic purposes $(24,25)$. Based on the checklist questionnaire provided to the children and parents, design 1 appeared to be well accepted. As seen in figure 1, the appliance with design 1 consisted of an anterior extension with several perforations, which provided good retention in the oral cavity. On the other hand, design 2 consisted of a buccal flap extension leading to poor retention because of the pushing action of the flap against the buccal mucosa. Similarly, the serrated borders in design 3 allowed for the escape of saliva through the gaps, thereby resulting in poor retention of the appliance in the oral cavity.

\section{Conclusions}

The findings of this study provide information about the attitudes and awareness of dental practitioners with regard to lip, cheek, and tongue biting in children who receive local anesthesia for dental treatment. The provision of adequate instructions to the patient is vital. The parent must monitor the child for a few hours after the treatment. Furthermore, among the three appliances fabricated in the current study to prevent self-injury in children, design 1 was most accepted and may be considered for use as a conservative approach for the management of self-inflicted soft tissue trauma in children following local anesthesia.

\section{References}

1. Chi D, Kanellis M, Himadi E, Asselin ME. Lip biting in a pediatric dental patient after dental local anesthesia: a case report. J Pediatr Nurs. 2008;23:490-3.

2. Vempaty S, Robbins J. Self-inflicted trauma secondary to local anaesthesia in children. Case Rep Dent. 2017;2017:4969484.

3. Jorgensen NB, Hayden J Jr. Complications from local anesthesia. Dent Clin North Am. 1965:591-99.

4. Nourbakhsh N, Shirani F, Babaei M. Effect of phentolamine mesylate on duration of soft tissue local anesthesia in children. J Res Pharm Pract. 2012;1:55-9.

5. Moore PA, Hersh EV, Papas AS, Goodson JM, Yagiela JA, Rutherford B, et al. Pharmacokinetics of lidocaine with epinephrine following local anesthesia reversal with phentolamine mesylate. Anesth Prog. 2008;55:40-8.

6. Fakheran Esfahani O, Pouraboutaleb MF, Khorami B. Effect of hydralazine on duration of soft tissue local anesthesia following dental treatment: a randomized clinical trial. Gen Dent. 2015;63:39-42.

7. Goldberg EM, Ferguson F. Treatment modalities for self-injurious behaviors observed in the special-needs patient: 2 case reports. Pediatr Dent. 2010;32:481-5.

8. Arhakis A, Topouzelis N, Kotsiomiti E, Kotsanos N. Effective treatment of self-injurious oral trauma in Lesch-Nyhan syndrome: a case report. Dent Traumatol. 2010;26:496-500.

9. Avashia Y, Bittar P, Suresh V, Powers DB. A novel approach for the management and prevention of self-induced masticatory lingual trauma in the neurologically injured patient. Craniomaxillofacial Trauma Reconstr. 2018;11:242-8.

10. Romero M, Vicente A, Bravo LA. Prevention of habitual cheek biting: a case report. Spec Care Dentist. 2005;25:214-6.

11. Bhatia SK, Goyal A, Kapur A. Habitual biting of oral mucosa: A conservative treatment approach. Contemp Clin Dent. 2013;4:386-9.

12. Shaheen R, Doumit M, Helal A. Design and characterization of a hyperelastic tubular soft composite. J Mech Behav Biomed Mater. 2017;75:228-35.

13. Cai J, Yang Y, Ai C, Jin W, Sheng D, Chen J, et al. Bone marrow stem cells-seeded polyethylene terephthalate scaffold in repair and regeneration of rabbit achilles tendon. Artif Organs. 2018;42:1086-94.

14. Alexandropoulos A, Al Jabbari YS, Zinelis S, Eliades T. Chemical and mechanical characteristics of contemporary thermoplastic orthodontic materials. Aust Orthod J. 2015;31:165-70.

15. Zhang N, Bai Y, Ding X, Zhang Y. Preparation and characterization of thermoplastic materials for invisible orthodontics. Dent Mater J. 2011;30:954-9.

16. Goldberg AJ, Burstone CJ. The use of continuous fiber reinforcement in dentistry. Dent Mater. 1992;8:197-202.

17. Becker DE, Reed KL. Essentials of local anesthetic pharmacology. Anesth Prog. 2006;53:98-108;quiz 109-10.

18. Peedikayil FC, Vijayan A. An update on local anesthesia for pediatric dental patients. Anesth essays Res. 2013;7:4-9.

19. College C, Feigal R, Wandera A, Strange M. Bilateral versus unilateral mandibular block anesthesia in a pediatric population. Pediatr Dent. 2000;22:453-7.

20. Ram D, Berson T, Moskovitz M, Efrat J. Unsweetened ice popsicles impart a positive feeling and reduce self-mutilation after paediatric dental treatment with local anaesthesia. Int J Paediatr Dent. 2010;20:382-8.

21. Cannavale R, Itro A, Campisi G, Compilato D, Colella G. Oral self-injuries: clinical findings in a series of 19 patients. Med Oral Patol Oral Cir Bucal. 2014;20:e123-9. 
22. Rana V, Srivastava N, Kaushik N, Panthri P. Cheek Plumper: An innovative anti-cheek biting appliance. Int J Clin Pediatr Dent. 2016;9:146-8.

23. Flaitz CM, Felefli S. Complications of an unrecognized cheek biting habit following a dental visit. Pediatr Dent. 2000;22:511-12.

24. Ercoli F, Tepedino M, Parziale V, Luzi C. A comparative study of two different clear aligner systems. Prog Orthod. 2014;15:31.

25. Hahn W, Engelke B, Jung K, Dathe H, Kramer FJ, Rodig T, et al. The influence of occlusal forces on force delivery properties of aligners during rotation of an upper central incisor. Angle Orthod. 2011;81:1057-63.

Acknowledgment

The authors would like to express gratitude to King Khalid University, Abha for its constant support in accomplishment of this study.

\section{Sources of support funding}

None.

\section{Conflicts of Interest}

Nil. 